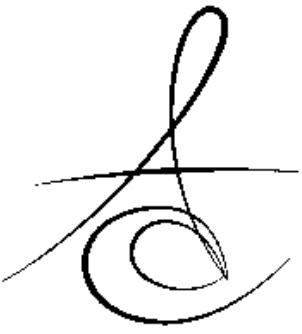

\section{FAZLA MADDE KAYIPLI DİŞLERİN İNDİREKT YÖNTEM İLE KONSERVATİF TEDAVİSİ: 4 OLGU SUNUMU}

\section{THE INDIRECT CONSERVATIVE TREATMENT APPROACH FOR THE TOOTH THAT HAS EXCESSIVE LOSS OF STRUCTURE: 4 CASE REPORTS}

\author{
Yrd. Doç. Dr. Neslihan TEKÇE \\ Dt. Hale KARAKUYU*
}

Makale Kodu/Article code: 1994

Makale Gönderilme tarihi: 30.11 .2014

Kabul Tarihi: 30.04.2015

\section{ÖZET}

$\mathrm{Bu}$ olgu sunumunda, aşırı madde kaybı bulunan dişlere, konservatif yaklaşım ile indirekt kompozit restorasyonlar yapılarak, bu tedavi seçeneğinin klinik başarısını değerlendirmek amaçlanmıştır. Kliniğimize başvuran 4 farklı hastanın 6 molar/premolar dişi, indirekt yöntem ile restore edilmeye karar verilmiştir. Hastalardan alınan ölçüler üzerine Tescera kompozit materyali (A2 shade, body, Bisco, Schaumburg, IL, USA) uygulanarak modelaj yapılmış ve arkasından Tescera indirekt kompozit fırınında (ATL II, Bisco, Schaumburg, IL, USA) önce ışık ile arkasından basınç ve ISı ile post-cure polimerizasyon işlemi yapılarak polimerizasyon işlemi tamamlanmıştır. Restorasyonların kavitelere uyumlanmasının arkasından, Duolink dual-cure yapıştırıcı siman ile yapıştırılmış ve cila işleminin tamamlanması ile restorasyonlar bitirilmiştir. Klinik olarak direkt yöntem ile ideal estetik, kontak ve uyumun sağlanamadığı aşırı madde kayıplı dişlere, ağız dışında hazırlanarak uyumlandırılan materyallerin uygulanması, immediat dönemde klinik olarak başarılı ve kabul edilebilir bir sonuç sergilemiştir.

Anahtar Kelimeler: Indirekt kompozitler, self-cure yapıştırıcı siman.

\section{ABSTRACT}

The aim of this case report was to evaluate the performance of conservative approach for the teeth which have excessive material loss, restored with indirect method and the clinical success of this treatment option. Four different patients admitted to our clinic and their 6 molar/or premolar teeth were decided to restore with indirect method. Replicas were prepared with silicon impression material. Tescera composite material (A2 shade, Bisco, Schaumburg, IL, USA) was applied on models and then it was polymerized using light, under the pressure and heat in Tescera indirect composite oven (Bisco, Schaumburg, IL, USA). After adopting the restorations to the cavities, they were luted with Duolink dual-cure luting cement. Restorations were completed after polishing and finishing procedures. The materials that were prepared out of the mouth exhibited successful conclusions clinically at immediate period with ideal esthetic, contact and compliance which is not achieved with direct method to teeth which have excessive loss of material.

Keywords: Indirect composites, self-cure luting cements.

\section{GİRIŞ}

Son yıllarda, ön-arka bölge restorasyonlarda kompozit materyallerin kullanımı önemli ölçüde artmıştır. ${ }^{12}$ Materyallerin içeriğinin güçlendirilmesi, dentin bonding ajanların dişe yüksek bağlanma sergilemeleri ve hastaların artan estetik beklentileri bu artış üzerinde etkili olmuştur. ${ }^{3,4}$ Estetik kaygıların dışında, amalgam restorasyonların zamanla korozyona uğraması, yapısında civa bulundurması sebebiyle de birçok klinisyen günümüzde amalgam restorasyonlar yerine kompozit restorasyonları tercih etmektedir. ${ }^{4,5}$

\footnotetext{
* Kocaeli Üniversitesi Diş Hekimliği Fakültesi Restoratif Diş Tedavisi AD.

**istanbul Üniversitesi Diş Hekimliği Fakültesi Restoratif Diş Tedavisi AD.
} 
Sık tercih edilmekle birlikte, kompozit materyallerin hala giderilememiş bir takım olumsuz özellikleri bulunmaktadır. ${ }^{6}$ Kompozit materyalinde görülen polimerizasyon büzülmesi bunların başında gelmektedir. Polimerizasyon büzülmesi, ara yüzde stres oluşturarak bağlanma bütünlüğünün süreye bağlı olarak bozulmasına sebep olmaktadır. ${ }^{7}$ Geniş arka bölge restorasyonlarda, özellikle de servikal kenarları dentinde sonlanan kavitelerde oluşan büzülme streslerinin, bonding ajanın dişe bağlanma kuvvetlerini aşması sonucu, restorasyonlarda kenar bozulmaları oluşabilir ve bunun sonucunda mikrosızıntı gelişir. ${ }^{8,9}$ Mikrosızıntı ise, kenar renkleşmesi, post-operatif hassasiyet, sekonder çürük ve pulpal irritasyona neden olarak restorasyonların uzun dönem başarısı üzerinde etkili olur. ${ }^{10}$

İndirekt kompozit sistemler, direkt kompozitlerde görülen bir takım olumsuzlukları ortadan kaldırmak için geliştirilmiştir. ${ }^{11}$ İlk olarak geliştirilen indirekt kompozit sistemi 1980'li yıllarda piyasaya sürülmüştür. ${ }^{12} \mathrm{Bu}$ sistemler, inley, onley, lamine veneer, jaket kron, implant destekli restorasyonlar gibi pek çok kullanım endikasyonuna sahiptirler. ${ }^{7,13}$ İndirekt ve direkt restoratif materyaller içerik olarak aynı olmakla birlikte, yapıya katılan organik ve inorganik içerik miktarında yapılan değişiklikler sebebiyle birbirlerinden farklılık göstermektedirler. ${ }^{7}$ Çoğu indirekt restoratif materyal hacimsel olarak daha yüksek oranlarda inorganik doldurucu içerdiği gibi, materyale ilave edilen partikülün büyüklüğü de fazladır. ${ }^{7}$ İndirekt kompozitlerde materyallerde doldurucu içeriğinin ve partikül büyüklüğünün artması sonucu monomer oran azalır. İnorganik içeriğin gelişmesi materyalin mekanik özelliklerini geliştirdiği gibi, materyallerde meydana gelen polimerizasyon büzülmesinin de azalmasına sebep olur. Polimerizasyon büzülmesinin azalmasında, monomer içeriğinin azalmasından başka kompozitin ağız dışında ilave polimerizasyon yöntemleri ile polimerize edilmesinin de etkisi vardır. ${ }^{14-16}$ Uygulanan ilave polimerizasyon yöntemleri ile monomerin polimere dönüşüm oranı artar, böylece materyalin su emilim oranı azalır ${ }^{14-18}$ ve bütün bunların sonucunda materyallerin özellikleri gelişerek, ağız içi kullanım ömürleri uzar.

İndirekt kompozit sistemlerde polimerizasyon yöntemleri; ışık ile aktivasyonun yanı sıra ısı ve basınç uygulamasını da içermektedir. ${ }^{11}$ Bu materyallerde ısı ile ilave polimerizasyon yapılması, materyalin yapısında daha az oranda stres oluşmasına sebep olmaktadır. Ayrıca, polimerizasyon büzülmesinin ağız dışında gerçekleşmesi sebebiyle, materyalde oluşan büzülme alanı diş-kompozit arasında kalmaktadır. ${ }^{19,20}$ Büzülme sonucu oluşan bu boşluğun daha sonra siman ile dolması ise ara yüzde stresi oluşmasını azaltır /önler. ${ }^{19}$

İndirekt restorasyonlarda bağlanma hem dual-cure simanlar hem de Işıkla polimerize olan simanlar ile sağlanır. ${ }^{21,22}$ Dual-cure simanlar, az ışık varlığında bile polimerizasyon sağlayan 'self-cure' komponentlere sahip olduklarından, hem ışıkla hem de kendi kendine polimerize olabilirler. ${ }^{23}$ Fakat fazla akışkan olmaları ve iki pat sisteminden oluşmaları en önemli dezavantajlarıdır. ${ }^{24}$

Geniş kavitelerde, kompozit materyalinin kaviteye yerleştirilmesi ve uyumlanması esnasında yaşanan problemler, indirek yöntem ile en aza indirilmiştir. Laboratuar ortamında, restorasyonların uygun proksimal kontur ve kontakların sağlanması ve ideal anatomik yapının oluşturulması daha kolaydır. ${ }^{25} \mathrm{Bu}$ nedenle bu olgularda, direk yöntem ile ideal kenar uyumu ve kontakların sağlanamadığı geniş kavitelerde, indirekt kompozit materyali Tescera ATL sistemi kullanılarak, farklı tip ve büyüklüklerdeki restorasyonlar tamamlanmıştır.

\section{OLGU 1}

16 yaşındaki bayan hasta (P.A.) kliniğimize ortodontik tedavi öncesi restoratif tedavilerinin yapılması için yönlendirilmiştir. Hastadan alınan medikal anamnezde herhangi bir sistemik hastalığının olmadığı öğrenilmiştir. Yapılan klinik ve radyolojik muayene sonucu hastanın sol alt birinci molar dişinde kenar uyumu bozulmuş olan eski bir amalgam restorasyon (Figür 1) bulunduğu ve dişe daha önceden kanal tedavisi yapıldığı tespit edilmiştir. Ortodontik tedavi amacı ile 36 numaralı dişe ortodontik bant yerleştirilmek istenmekte, ancak braket yerleştirilmesi için yeterli dikey boyut mesafesi bulunmaması sebebiyle, dişin adeziv materyaller ile güçlendirilmesi istenmektedir. Dişteki aşırı madde kaybı göz önünde bulundurulduğunda, dişe indirekt bir restorasyon yapılması uygun görülmüştür. Kavite elmas frezler (Diamond Bur, SWS Dental, LOT: K8063) ile düzenlenmiş (Figür 2), kavite tabanına kaide maddesi olarak geleneksel cam iyonomer siman (Meron, voco, Germany) yerleştirilmiştir. Diş etrafına retraksiyon ipi 
Atatürk Üniv. Diş Hek. Fak. Derg.

] Dent Fac Atatürk Uni

Supplement: 13, YIl: 2015, Sayfa : 23-31

yerleştirildikten sonra C tipi silikon ölçü maddesi (Zetaplus, Zhermack, Italy) ile ölçü alınarak (Figür 3) ve ışıkla sertleşen geçici dolgu materyali (DiaTemp, DiaDent, Netherlands) ile kapatılmıştır. Ölçüler yüksek sertliğe sahip silikon day materyali (Quick Die, Schaumburg, IL, USA) ile dökülmüş, model üzerinde A2 renginde indirekt kompozit materyali ((Tablo1), Tescera, body, Schaumburg, IL, USA) ile restorasyon uyumlanmış ve 20 sn görünür ışık ile (Elipar S10, 3M, ESPE, St Paul MN, USA) ön polimerizasyon sağlanmıştır. Elde edilen restorasyon Tescera ATL II (Bisco, Schaumburg, IL, USA) indirekt kompozit pişirme fırınına konularak $4 \mathrm{dk}$ süre ile ışık siklusuna tabi tutulmuştur (Figür 4). Daha sonra restorasyon yarısı su ile doldurulmuş sepete yerleştirilmiş (Figür 5) ve $25 \mathrm{dk}$ boyunca basınçlı su fırınında ISı ve basınç işlemine tabi tutulmuş ve böylelikle kompozitin polimerizasyon işlemi tamamlanmıştır. Restorasyon elmas frezler yardımıyla kaviteye uyumlandırımıştır. Kavitenin tüm yüzeylerine 15 sn fosforik uygulanmış ve asit 30 saniye süreyle yıkanarak uzaklaştırılmıştır. Kavite kurutulduktan sonra tüm yüzeylere adeziv rezin (All Bond Universal, Bisco, Schaumburg, IL, USA) bir aplikatör yardımıyla 10-15 saniye süreyle ovalayarak uygulanmış ve üretici firma önerilerine göre bu işlem iki tabaka olarak tekrar edilmiştir (Figür 6, Tablo 1). Adezivin üzerine 10 sn süreyle basınçlı hava tutularak rezinin tüm diş yüzeyine homojen ve ince bir tabaka halinde yayılması sağlanmıştır. 1200mW gücündeki ELİPAR S10 görünür ışık uygulaması ile 10 sn ışık uygulanarak adezivin polimerizasyonu sağlanmıştır. Restorasyonun iç yüzeyine aynı adeziv (All Bond Universal, Bisco, Schaumburg, IL, USA) sistem bu sefer tek tabaka olarak uygulanmış ve 10 sn süresince ışık ile polimerize edilmiştir (Figür 7). Restorasyon dual-cure rezin modifiye siman (Duo-Link, Bisco, Schaumburg, IL, USA) ile yapıştırılmış (Figür 8, 9), kavite kenarlarından taşan fazlalıklar bir pamuk pelet ile temizlenmiş ve dual-cure simanın polimerizasyonu için tüm yüzeylerden 40sn ışık uygulanmıştır. Yükseklik artikülasyon kağıdı ile kontrol edilmiş, sarı bantlı elmas

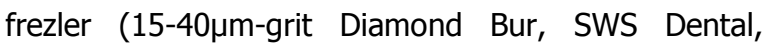
Turkey LOT:140738 ) ve diskler (Soflex, 3M ESPE, MN, USA) yardımıyla bitirme ve cila işlemleri tamamlanmıştır (Figür 10).
TEKÇE, GÖKTÜRK,

KARAKUYU, TUNCER

Tablo 1: Çalışmada kullanılan dentin bonding ajan, yapıştırıcı siman, kompozit içerik ve uygulama prosedürü.

\begin{tabular}{|c|c|c|c|}
\hline Materyal & İçerik & Doldurucu & $\begin{array}{l}\text { Uygulama } \\
\text { Prosedürü }\end{array}$ \\
\hline $\begin{array}{l}\text { Duolink } \\
\text { Yapıştırıcı } \\
\text { Siman } \\
\text { (Bisco } \\
\text { Schaumburg, } \\
\text { USA) }\end{array}$ & $\begin{array}{l}\text { Base: bis-GMA, } \\
\text { TEG-DMA, glass } \\
\text { filler, urethane } \\
\text { dimethacrylate, } \\
\text { CQ, tertiary } \\
\text { amine. } \\
\text { Catalyst: bis-GMA, } \\
\text { TEG-DMA, glass } \\
\text { filler, benzoyi } \\
\text { peroxide }\end{array}$ & $\begin{array}{l}\text { Ağırlıkça \%60; } \\
\text { Hacimce \%38 } \\
\text { doldurucu. } \\
\text { Partikül } \\
\text { büyüklüğü; } \\
<1.0 \mu m\end{array}$ & \begin{tabular}{|l} 
Duolink hem \\
kaviteye hem de \\
restorasyonun alt \\
yüzeyine uygulanır. \\
Restorasyon \\
kaviteye \\
yerleştirilerek \\
yapıstıııı simanın \\
fazlalıkları bir pelet \\
ile temizlenir. \\
40 sn her bir \\
yüzeyden ışı verilir.
\end{tabular} \\
\hline $\begin{array}{l}\text { All Bond } \\
\text { Universal } \\
\text { (Bisco } \\
\text { Schaumburg, } \\
\text { USA) }\end{array}$ & $\begin{array}{l}\text { MDP phosphate } \\
\text { monomer } \\
\text { bis-GMA } \\
\text { HEMA } \\
\text { Ethanol } \\
\text { Water } \\
\text { Initiators }\end{array}$ & - & $\begin{array}{l}\text { Mine ve dentin } \\
\text { yüzeylerine } 15 \mathrm{sn} \\
\text { asit uygulanır ve } \\
\text { yıkanır. } 2 \text { tabaka } \\
\text { bonding kaviteye } \\
\text { sürülür ve her bir } \\
\text { tabaka } 10-15 \mathrm{sn} \\
\text { ovalanarak } \\
\text { uygulanır. } 10 \mathrm{sn} \text { ışık } \\
\text { verilir. }\end{array}$ \\
\hline $\begin{array}{l}\text { Tescera } \\
\text { indirekt } \\
\text { kompozit, } \\
\text { body } \\
\text { (Bisco } \\
\text { Schaumburg, } \\
\text { USA) }\end{array}$ & $\begin{array}{l}\text { Amorphous silica, } \\
\text { glass frit, } \\
\text { TEGDMA, BisGMA, } \\
\text { camphoroquinone, } \\
\text { tertiary amin, } \\
\text { TBPZ (heat } \\
\text { initiator) }\end{array}$ & $\begin{array}{l}\text { Ağırlıkça \%81; } \\
\text { Hacimce \%66 } \\
\text { doldurucu. } \\
\text { Partikül } \\
\text { büyüklüğü: } \\
\text { yaklaşık (0.05 } \\
\mu \mathrm{m}) .\end{array}$ & - \\
\hline
\end{tabular}

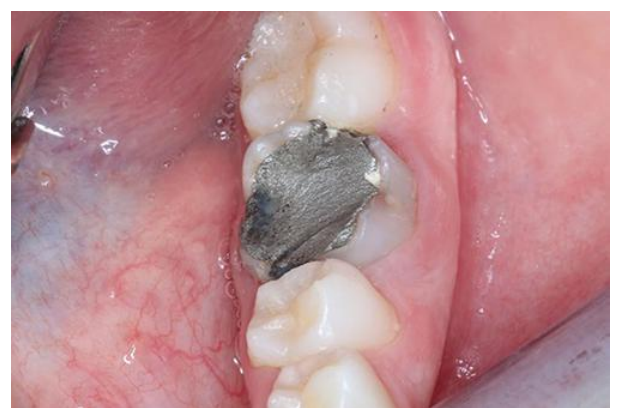

Figür 1. Olgu 1, 36 numaralı dişteki eski amalgam restorasyonun klinik görüntüsü

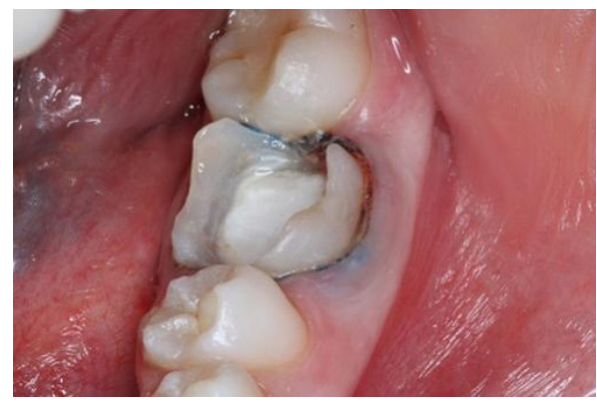

Figür 2. 36 numaralı dişin eski restorasyonun sökümünden ve retraksiyon ipi uygulandıktan sonraki görüntüsü 


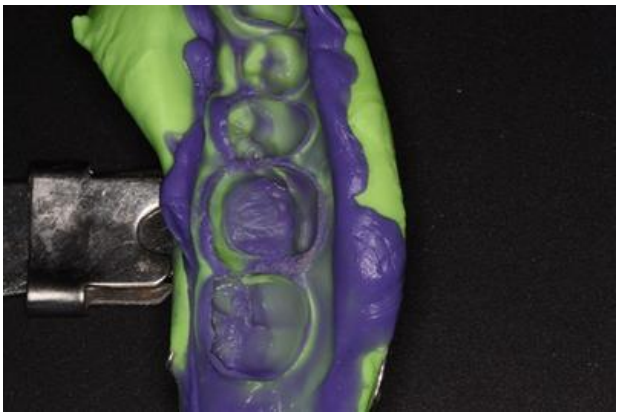

Figür 3. Ölçü

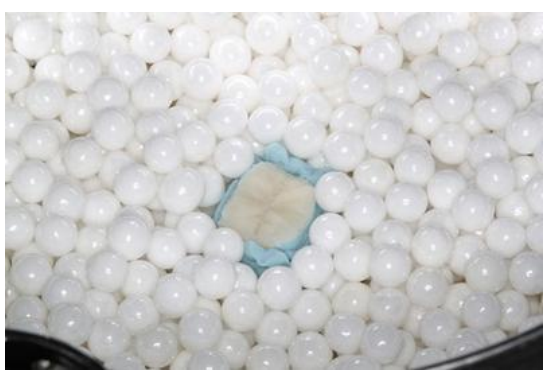

Figür 4. Tescera ATL II cihazının ışık haznesi

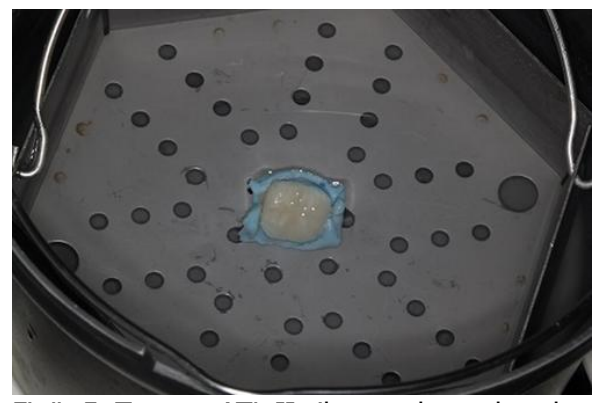

Figür 5. Tescera ATL II cihazının basınçlı su haznesi

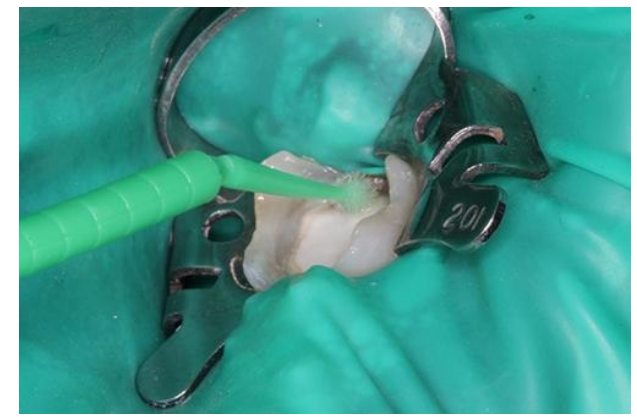

Figür 6. Kaviteye bonding uygulaması

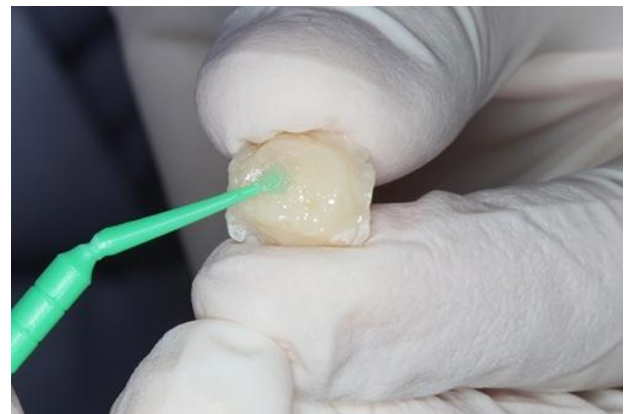

Figür 7. Tescera indirekt kompozitin iç yüzeyine bonding uygulaması

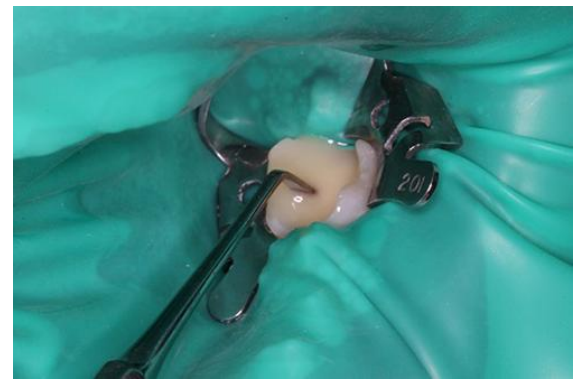

Figür 8. Duo-link yapıştıııı simanın kaviteye uygulanmas

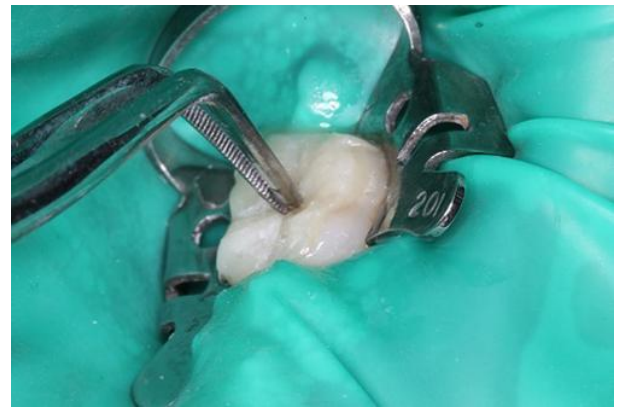

Figür 9. Kompozit materyalinin kaviteye yerleştirilmesi

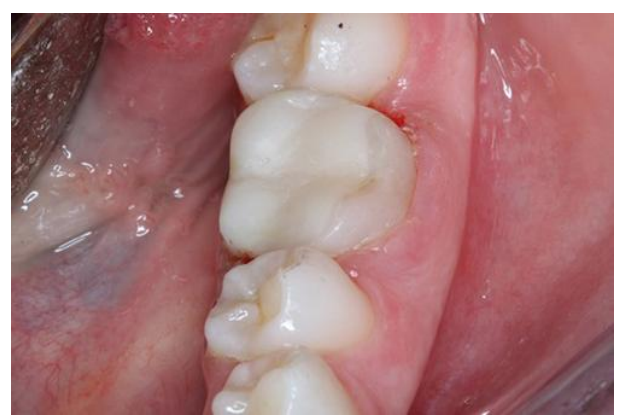

Figür 10: 36 numaralı dişin restorasyonunun bitmiş hali

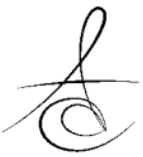




\section{OLGU 2}

17 yaşındaki bayan hasta 25, 26 numaralı dişlerindeki (Figür 11) termal hassasiyet, fonksiyon kaybı ve dolgularındaki renk değişimi şikayetiyle kliniğimize başvurmuştur. Alınan medikal anamnezinde hastada mitral kapak defekti olduğu öğrenilmiştir. Doktoru ile yapılan konsültasyon sonucu dental tedavilerinin antibiyotik proflaksisi altında yapılması uygun görülmüştür. Yapılan radyolojik ve klinik muayene sonucu üst sol ikinci premolar ve üst sol birinci molar dişlerindeki eski restorasyonlarda kenar renklenmesi ve sekonder çürük tespit edilmiştir. Radyolojik muayenede üst sol birinci molar dişinde kanal tedavisi olduğu görülmüş fakat yenilenmesine gerek duyulmamıştır. Kaviteler minimum madde kaybı hedeflenerek elmas frezler (SWS Dental, Turkey, LOT: K8063) ile düzenlenmiştir. 26 numaralı dişe kaide maddesi olarak ışıkla sertleşen kaide materyali (Glass Liner, WP Dental, Germany) yerleştirilmiş ve kavite duvarlarındaki undercutlar bu materyal ile bloke edilmiştir. 25 numaralı dişe herhangi bir materyal uygulanmamıştır. Çenelerden C tipi silikon ölçü maddesi (Zetaplus, Zhermack, Italy) ile ölçü alınmış, ölçülere laboratuarda yüksek sertliğe sahip silikon day materyali (Quick Die, Bisco, Schaumburg, IL, USA) dökülmüştür. Kaviteler ışıkla polimerize olan geçici dolgu materyali (DiaTemp, DiaDent, Netherlands) ile kapatılmıştır. Model üzerinde dişlere $\mathrm{A} 2$ renginde indirekt kompozit materyali (Tescera, Bisco, Schaumburg, IL, USA) uygulanmış, 1. olgu raporunda olduğu gibi, üretici firma önerileri doğrultusunda polimerize edilmiş, dişe uyumlandırılmış ve Duo-link dual-cure siman aracılığı ile dişe yapıştırılmıştır (Figür 12).

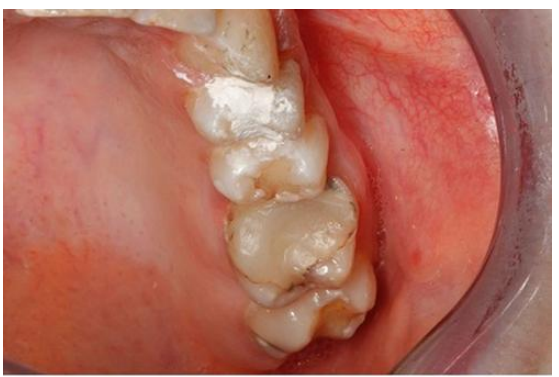

Figür 11. Olgu 2, 25 ve 26 numaralı dişlerdeki eski kompozit restorasyonlar

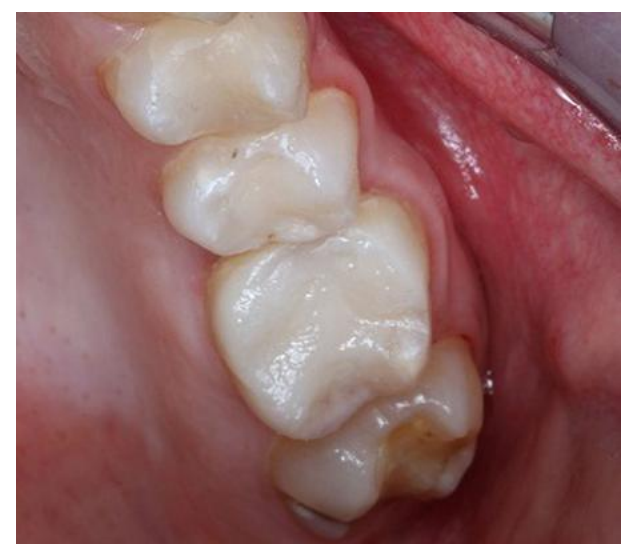

Figür 12. 25 ve 26 numaralı dişlerin indirekt kompozit restorasyonlarının bitmiş hali

\section{OLGU 3}

14 yaşındaki erkek hasta (Y.Y.) kanal tedavisi sonrası 26 no'lu dişinin restorasyonu (Figür 13) için Restoratif Diş Tedavisi ABD’na başvurmuştur. Hastadan alınan medikal anamnezde herhangi bir sistemik hastalığı olmadığı öğrenilmiştir. Yapılan klinik ve radyolojik muayene sonucu dişteki aşırı madde kaybı nedeniyle indirekt bir restorasyon uygulanmasına karar verilmiştir. Kavite elmas frezler yardımıyla düzenlenmiş, tungsten karbid frezler (Tungsten Carbid Bur, Medin, Czech Republic,LOT:12808895) ile çürük dentin temizlenmiş, undercut bölgeleri elimine edilmiştir. Kanal ağızları ışıkla sertleşen radyoopak kaide materyali (Glass Liner, WP Dental, Germany) ile örtülmüştür. Çenelerden ölçü alınmış (Zetaplus, Zhermack, Italy), ölçülere laboratuarda yüksek sertliğe sahip silikon day materyali (Quick Die, Bisco, Schaumburg, IL, USA) dökülmüştür. Kaviteler Işıkla polimerize olan geçici dolgu materyali (DiaTemp, DiaDent, Netherlands) ile kapatılmıştır. Model üzerinde dişlere A2 renginde indirekt kompozit materyali (Tescera, Bisco, Schaumburg, IL, USA) uygulanmış 1. olgu raporunda olduğu gibi, üretici firma önerileri doğrultusunda polimerize edilmiş, dişe uyumlandırılmış ve Duo-link dual-cure siman aracılığı ile dişe yapıştırılmıştır (Figür 14). 


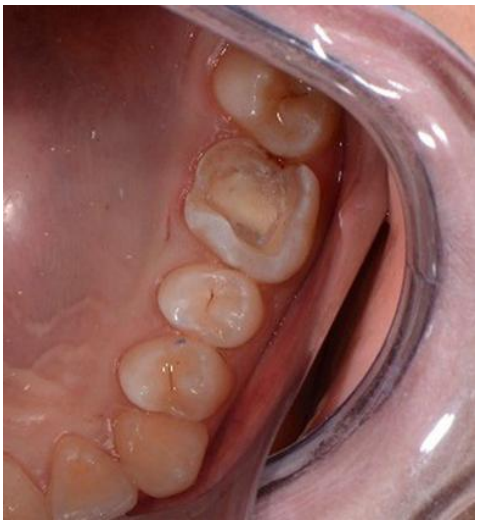

Figür 13. Olgu 3, 26 numaralı diş

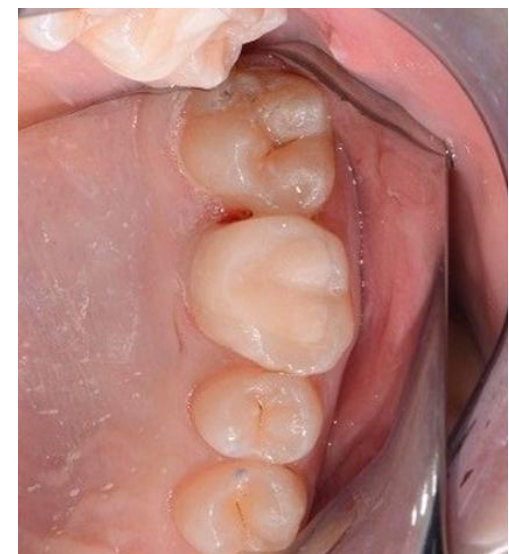

Figür 14. 26 numaralı dişin indirekt kompozit restorasyonun bitmiş hali

\section{OLGU 4}

13 yaşındaki erkek hasta 36 ve 46 no'lu dişlerindeki (Figür 15, 17) sıcak-soğuk hassasiyeti şikayeti ile kliniğimize gelmiştir. Alınan medikal anamnezde hastada herhangi bir sistemik hastalık bulunmadığı ebeveynlerinden öğrenilmiştir. Yapılan klinik ve radyolojik muayene sonucu 36 no'lu dişte kenar renkleşmesi ile beraber okluzal yüzeyde aşınma, 46 numaralı dişte ise kenar renkleşmesine ek olarak dişin mesial duvarında sekonder çürük teşhis edilmiştir. Eski restorasyonlar uzaklaştırıldıktan sonra çürükler elmas frezler (Diamond Bur, SWS Dental, Turkey, LOT: 46579) ve karbid frezler (Tungsten Carbid Bur, Medin, Czech Republic, LOT:12808895) yardımıyla temizlenmiş, sağlıklı sert yapıdaki dentine ulaşıldığında çürük temizleme işlemi sonlandırımıştır. Çürüğün temizlenmesinin arkasından undercutlar ortadan kaldırımıştır. Dişlerden ölçü alınarak (Zetaplus, Zhermack, Italy), A2 renginde indirekt kompozit materyali (Tescera, Bisco, Schaumburg, IL, USA) uygulanmış 1 . olgu raporunda olduğu gibi, üretici firma önerileri doğrultusunda polimerize edilmiş, dişe uyumlandırımış ve Duo-link dual-cure siman aracılığı ile dişe yapıştırılmıştır (Figür 16, 18).

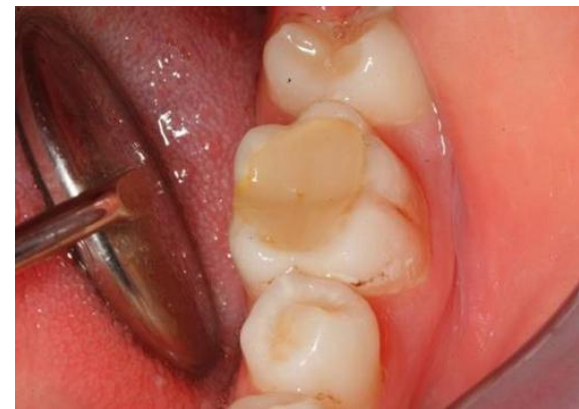

Figür 15. Olgu 4, 36 numaralı dişteki eski kompozit restorasyon

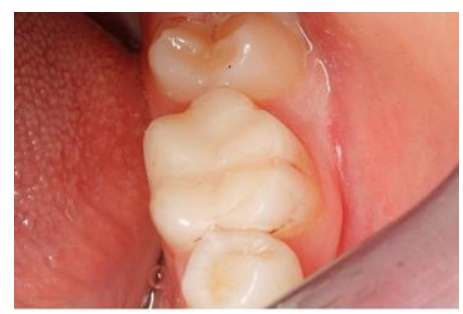

Figür 16. 36 numaralı dişin indirekt kompozit inley restorasyonun bitmiş hali

\section{TARTIŞMA}

Son 20 yıldır, kompozit inley sistemler, direkt yöntem ile uygulanan kompozit sistemlere bir alternatif olarak sıklıkla kullanılmaktadır. Geleneksel kompozitler ile yaşanan sorunlar genellikle; polimerizasyon büzülmesi, okluzal ve proksimal aşınmalar, yüzey pürüzlülüğü, kompozitte kenar ve yüzey renkleşmesi ve postoperatif hassasiyettir. ${ }^{26}$

Özellikle polimerizasyon büzülmesi ve bunun sonucu ara yüzde oluşan stresler, kompozit restorasyonlarda yaşanan sorunların önemli bir kısmını oluşturmaktadır. Günümüzde polimerizasyon büzülme ve büzülme streslerini azaltmak için kompozit mateyali tabakalama tekniği ile uygulanmakta, sandvich tekniği gibi yöntemler ile kompozitin altına stres absorbe edici bir materyaller ile ara yüzde oluşan streslerin azaltılması amaçlanmakta ya da indirekt kompozitler kullanılmaktadır. ${ }^{27}$

Restorasyonlarda kenar bütünlüğü, restorasyonların başarısını belirleyen en önemli paramet- 
relerden biridir. Aşınma direnci çok yüksek olan postcured indirekt kompozit materyaline göre yapıştırıcı simanların aşınma direnci oldukça düşüktür. ${ }^{28}$ Scheibenbogen-Fuchsbrunner ve arkadaşları ${ }^{229}$ küçük kavitelerin kenar uyumlarının, büyük kavitelere oranla daha başarılı olduğunu bildirmişlerdir ve okluzal streslerin posterior geniş kaviteli dişlerde daha etkili olduğunu ileri sürmüşlerdir.

Douglas ve arkadaşları $^{30}$ direkt ve indirekt yöntem ile tamamlanan restorasyonların mikrosızıntılarını karşılaştırdıkları laboratuar çalışmasında, indirekt yöntem ile hazırlanan restorasyonların anlamlı olarak düşük boya sızıntısı sergilediklerini ifade etmişlerdir. Özakar ve arkadaşları ${ }^{31}$ direkt ve indirekt kompozitlerin mikrosızıntılarını kıyasladıkları çalışmada, en az mikrosızıntı değerlerinin Tescera ATL sistemle yapılan indirekt inleylerden elde edildiğini bildirmiştir. Araştırmacılar posterior bölgedeki sınıf II kavitelerde Tescera ATL sistemin direkt kompozit restorasyonlara iyi bir alternatif olduğunu ileri sürmüştür. Araştırmacılar Tescera ATL sistemin başarısını, bu sistemin oksijen bulunmayan bir ortamda (su haznesinin içerisinde) basınçlı ISı-ışık ünitesinde polimerize edilmesine bağlamışlardır. ${ }^{30}$ Peutzfeldt ve Asmussen $^{32}$ kompozit restorasyonlarda büzülme stresleri sonucu oluşan gap/boşluğun indirekt yöntem ile önlenebileceğini ileri sürmüşlerdir. Bu çalışmada dual cure rezin siman Duo-link kavitelere uygulanmadan önce All Bond Universal Bonding ajan kavitelere uygulanmıştır. Paul ve arkadaşları ${ }^{33}$ yapıştırıcı siman uygulamasından önce kavite yüzeylerine adeziv uygulanmasının kenar sızıntısı ve post-operatif hassasiyeti azalttığını bildirmişlerdir. Universal bonding sistemler son geliştirilen dentin bağlayıcılar olmakla birlikte, uygulayıcılara bağlayıcı ajanı hem self-etch hem de total-etch yaklaşımına göre uygulama olanağı sunmaktadırlar. Yapılan çalışmalar universal bağlayıcı ajanların asit uygulanması arkasından uygulanmasının,mine dokusuna olan bağlanma dayanım değerlerini arttırdığını ileri sürmüştür. ${ }^{33} \mathrm{Bu}$ nedenle bu çalışmada universal ajan diş dokusuna 15 sn asit uygulaması arkasından uygulanmıştır. Ayrıca bu sistemlerde bağlayıcı içeriğine 10-MDP katılması, diş dokusunda kalan hidroksiapatitlerle bağlayıcı ajan arasında ilave bir kimyasal bağlanma gerçekleşmesini sağlayarak mine ve dentin dokusuna olan bağlanmanın gelişmesine sebep olmaktadır. ${ }^{34}$ Dual cure rezin simanlar ışıkla ve kimyasal olarak sertleşirler ve $>3 \mathrm{~mm}^{\prime}$ den büyük kalınlıklarda uygulanabilirler. ${ }^{36}$ Hikita ve arkadaşları ${ }^{35}$ yapıştırıcı simanların mine dokusunda ortalama 35-50MPa mikrogerilim bağlanma dayanım değerleri ( $\mu \mathrm{TBS}$ ) sergilediklerini bildirirken, dentin dokusunda bu değerlerin 15-20 MPa'ya gerilediğini bildirmişlerdir. Yapıştırıcı simanların dentin dokusuna olan düşük bağlanma dayanım değerleri sebebiyle, bu çalışmada da kalan sağlıklı mine dokusu uzaklaştırılmadan, restorasyonlar olabildiğince mine duvarlarında sonlandırılmıştır.

Wassell ve arkadaşları ${ }^{27}$ geleneksel kompozit sistemler ile inley kompozitlerin 5 yıllık klinik takiplerini yaptıkları çalışmada, her iki kompozitin uzun dönem klinik başarıları arasında fark bulunmadığını bildirmişlerdir. Van Dijken ve arkadaşları ${ }^{16}$ inley/onley sistemlerin 6 yıl sonunda, geleneksel kompozitlerden daha iyi klinik performans sergilediklerini bildirirken, 11 yıl sonundaki klinik başarıları arasında anlamlı bir farklılık olmadığını ileri sürmüşlerdir. ${ }^{27}$ Araştırmacılar, inley restorasyonların klinik olarak aşınma oranlarının düşük olduğunu, çalışmaya dahil olan yalnızca 4 hastanın inley retorasyonlarında kırılma gerçekleştiğini, bunun sebebinin de 4 hastanın da ileri derecede buruksizimin bulunması olduğunu ifade etmişlerdir. Araştırmacılar, inley restorasyonlarda polimerizasyon büzülmesi ve büzülme streslerinin düşük olması sebebiyle kenar adaptasyonlarının da çok başarılı olduğunu ileri sürmüşlerdir. Condon ve Ferracane ${ }^{37}$ kompozit materyalinin aşınması ile doldurucu hacmi arasında doğru orantı olduğunu ileri sürmüşlerdir. Araştırmacılar, indirekt sistemlerde yüksek ISı ve basınç altında postcure işlemi uygulanmasının da materyalin aşınma direncinin gelişmesinde etkisinin olabileceğini ileri sürmüşlerdir. Bu araştırmacılardan farklı olarak, Catelan ve arkadaşları ${ }^{38}$ Filtek Z250 ile Sinfony indirekt kompozitin mikrosertlik, flexural strength ve kompozit dönüşüm oranını kıyasladıkları çalışmada, direkt restoratif materyalin (Filtek Z250) çalışmada incelenen bütün parametrelerde indirekt yöntemden yüksek değerler sergilediğini ileri sürmüşlerdir.

Sonuç olarak; yapılan laboratuar ve klinik çalışmalar incelendiğinde, özellikle aşırı madde kayıplı dişlerde geleneksel kompozit sistemler ile yaşanan bir takım problemler sebebiyle, indirekt sistemlerin kullanımı önerilmektedir. İlave polimerizasyon yöntemlerinin sağladığı avantajlar, renk stabilitesi, düşük su emilim oranı ve yüksek aşınma direnci gibi özellikler, 
indirekt restorasyonların her türlü kavite tipinde kullanımını büyük ölçüde yaygınlaştırmıştır. Ayrıca, ulaşılması zor olan arka bölge restorasyonlarında, ideal kontakt ve okluzal uyumun ağız dışında sağlanması, klinisyenlere kolaylık sağlamış, restorasyonların klinik başarısının artmasına sebep olmuştur. Bu sistemlerin sağladığı tüm bu avantajlar bu çalışmadaki vakalarda indirekt sistemi tercih etmemize sebep olmuş ve fazla madde kayıplı dişlerde indirek yöntem ile hazırlanarak dişe yapıştırılan kompozit materyallerin kullanımının kısa dönemde başarılı sonuçlar sergilediği izlenmiştir.

\section{KAYNAKLAR}

1. Baratieri LN, Ritter AV. Four-year clinical evaluation of posterior resin-based composite restorations placed using the total-etch technique. J Esthet Restor Dent 2001;13:50-7.

2. Fagundes TC, Barata TJ, Bresciani E, Cefaly DF, Jorge MF, Navarro MF. Clinical evaluation of two packable posterior composites: 2-year follow-up. Clin Oral Investig 2006;10:197-203.

3. Van Meerbeek B, De Munck J, Yoshida Y, Inoue S, Vargas M, Vijay $\mathrm{P}$, et al. Buonocore memorial lecture. Adhesion to enamel and dentin: current status and future challenges. Oper Dent 2003;28:215-35.

4. Christensen GJ. Esthetic dentistry and ethics. Quintessence Int 1989;20:747-53.

5. Dietschi D, Magne P, Holz J. Recent trends in esthetic restorations for posterior teeth. Quintessence Int 1994;25:659-77.

6. de Andrade OS, de Goes MF, Montes MA. Marginal adaptation and microtensile bond strength of composite indirect restorations bonded to dentin treated with adhesive and low-viscosity composite. Dent Mater 2007;23:279-87.

7. Touati B. The evolution of aesthetic restorative materials for inlays and onlays: a review. Pract Periodontics Aesthet Dent 1996;8:657-66.

8. Dietschi D, de Siebenthal G, Neveu-Rosenstand L, Holz J. Influence of the restorative technique and new adhesives on the dentin marginal seal and adaptation of resin composite Class II restorations: an in vitro evaluation. Quintessence Int 1995; 26: 717-27.

9. Dietschi D, Scampa U, Campanile G, Holtz J. Marginal adaptation and seal of direct and indirect class II composite resin restorations: an in vitro evaluation. Quintessence Int 1995;26:127-38.

10. Browne RM, Tobias RS. Microbial microleakage and pulpal inflammation: a review. Endod Dent Traumatol 1986;2:177-83.

11. Fonseca RB, Correr-Sobrinho L, Fernandes-Neto $\mathrm{AJ}$, Quagliatto PS, Soares CJ. The influence of the cavity preparation design on marginal accuracy of laboratory-processed resin composite restorations. Clin Oral Investig 2008;12:53-9.

12. Mormann WH. Composite inlays: a research model with practice potential. Quintessenz 1982;33:1891901.

13. Leinfelder KF. Indirect posterior composite resins. Compend Contin Educ Dent 2005;26:495-503.

14. Wendt SL Jr, Leinfelder KF. The clinical evaluation of heat-treated composite resin inlays. J Am Dent Assoc 1990;120:177-81.

15. Bessing C, Lundqvist P. A 1-year clinical examination of indirect composite resin inlays: a preliminary report. Quintessence Int 1991;22:1537.

16. Van Dijken JW. A 6-year evaluation of a direct composite resin inlay/onlay system and glass ionomer cement-composite resin sandwich restorations. Acta Odontol Scand 1994;52:368-76.

17. Wassell RW, Walls AW, McCabe JF. Direct composite inlays versus conventional composite restorations: three-year clinical results. $\mathrm{Br}$ Dent J 1995 11;179:343-9.

18. Gladys S, Van Meerbeek B, Inokoshi S, Willems G, Braem M, Lambrechts $P$, et al. Clinical and semiquantitative marginal analysis of four toothcoloured inlay systems at 3 years. J Dent 1995;23:329-38.

19. Khan AM, Satou N, Shintani H, Taira M, Wakasa K, Yamaki M. Effects of post-curing by heat on the mechanical properties of visible-light cured inlay composites. J Oral Rehabil 1993;20:605-14.

20. Van Dijken JWV, Horstedt P. Marginal breakdown of 5-year old direct composite inlays. J Dent 1996;24:389-94.

21. Ferrari M, Dagostin A, Fabianelli A. Marginal integrity of ceramic inlays luted with a self-curing resin system. Dent Mater 2003;19:270-6.

22. 
23. Irie M, Suzuki K. Current luting cements: marginal gap formation of composite inlay and their mechanical properties. Dent Mater 2001;17:34753.

24. Radovic I, Monticelli F, Goracci C, Vulicevic ZR, Ferrari M. Self-adhesive resin cements: a literature review. J Adhes Dent 2008;10:251-8.

25. Aravamudhan K, Rakowski D, Fan PL. Variation of depth cure and intensity with distance using LED curing lights. Dent Mater 2006;22:988-94.

26. Manhart J, Chen HY, Hamm G, Hickel R. Buonocore memorial lecture review of the clinical survival of direct and indirect restorations in posterior teeth of the permanent dentition. Oper Dent 2004;29:481-508.

27. Wassell RW, Walls AWG, McCabe JF. Direct composite inlays versus conventional composite restorations: 5-year follow-up. J Dent 2000;28:375-82.

28. Van Dijken JWV. [Direct resin composite inlays/onlays: an 11 year follow-up]. J Dent 2000;28:299-306.

29. Scheibenbogen-Fuchsbrunner A, Manhart J, Kremers L, Kunzelmann KH, Hickel R. Two-year clinical evaluation of direct and indirect composite restorations in posterior teeth. J Prosthet Dent 1999;82:391-7.

30. Douglas WH, Fields RP, Fundingsland J. A comparison between the microleakage of direct and indirect composite restorative systems. J Dent 1989;17:184-8.

31. Özakar-İlday N, Urvasızoglu N, Seven N. İndirect inley restorasyonlar ile direkt kompozit restorasyonların mikrosızıntı yönünden karşılaştırılması. Atatürk Üniv Diş Hek Fak Derg 2009;19:76-84.

32. Peutzfeldt A, Asmussen E. A comparison of accurancy in seating and gap formation for three inlay/onlay techniques. Oper Dent 1990;15:12935.

33. Paul SJ, Schärer P. The dual bonding technique: a modified method to improve adhesive luting procedures. Int J Periodont Rest Dent 1997; 17: 536-45.
34. Munoz MA, Sezinando A, Luque-Martinez I, Szesz $A L$, Reis $A$, Loguercio $A D$, et al. Influence of hydrophobic resin coating on the bonding efficacy of three universal adhesives. J Dent 2014;42:595602.

35. Yoshida Y, Nagakane K, Fukuda R, Nakayama Y, Okazaki M, Shintani $S$, et al. Comparative study on adhesive performance of functional monomers. ] Dent Res 2004;83:454-8.

36. Hikita K, Meerbeek BV, De Munck J, Ikeda T, Van Landuyt $K$, Maida $T$, et al. Bonding effectiveness of adhesive luting agents to enamel and dentin. Dent Mater 2007;23:71-80.

37. Condon JR, Ferracane JL. In vitro wear of composite with varied cure, filler treatment. J Dent Res 1997;76:1405-11.

38. Catelan A, Santo MR, Menegazzo LM, Moraes JC, dos Santos PH. Effect of light curing modes on mechanical properties of direct and indirect composites. Acta Odontol Scand 2013;71:697-702.

\section{Yazışma Adresi}

Neslihan Tekçe

Kocaeli Üniversitesi

Diş Hekimliği Fakültesi,

Restoratif Diş Tedavisi ABD

Yuvacık yerleşkesi, KOCAELİ

Tel: 02623442222

E-posta: neslihan_arslann@hotmail.com 